\title{
Long-term Effects of Inorganic Fertilizer and Compost Application on Rice Sustainability in Paddy Soil
}

\author{
Chang Hoon Lee*, Chang Young Park ${ }^{1}$, Ki Youl Jung ${ }^{1}$, and Seong Soo Kang \\ Soil and Fertilizer Management Division, NAAS, RDA, Suwon, 441-707, South orea \\ ${ }^{1}$ FunctionalCereal Crop Research Division, NCSI, RDA, Miryang, 1085, South Korea
}

(Received: May 10 2013, Accepted: June 3 2013)

\begin{abstract}
Sustainability index was calculated to determine the best management for rice productivity under long-term inorganic fertilizer management's practices. It is based on nutrient index, microbiological index and crop index related to sustainability as soil function. Indicators for calculating sustainability index were selected by the comparison of soil properties and rice response in paddy soil with fertilization. Total twenty two indicators were determined to assess nutrient index, microbiological index and crop index in order to compare the effect of different fertilization. The indices were applied to assess the sustainability with different inorganic fertilizer treatments such as control, N, NK, NP, NPK, NPK+Si, and NPK+Compost. The long-term application of compost with NPK was the highest sustainability index value because it increased nutrient index, microbial index and crop index. The use of chemical fertilizers resulted in poor soil microbial index and crop index, but the treatments like NP, NPK, and NPK+Si were maintained sustainability in paddy soil. These results indicate that application of organic and chemical fertilizer could be a good management to improve rice sustainability in paddy soil.
\end{abstract}

Key words: Sustainability, Fertilization, soil fertility, Paddy soil

Sustainable index in paddy soil applied with different fertilization for 42 years.

\begin{tabular}{lcccc}
\hline \hline Treatments & $\begin{array}{c}\text { Nutrient } \\
\text { index }\end{array}$ & $\begin{array}{c}\text { Microbiological } \\
\text { index }\end{array}$ & $\begin{array}{c}\text { Crop } \\
\text { index }\end{array}$ & $\begin{array}{c}\text { Sustainability } \\
\text { index }\end{array}$ \\
\hline Control & $0.791^{\mathrm{bc}}$ & $0.819^{\mathrm{d}}$ & $0.579^{\mathrm{d}}$ & $0.696^{\mathrm{f}}$ \\
$\mathrm{N}$ & $0.888^{\mathrm{bc}}$ & $0.833^{\mathrm{d}}$ & $1.010^{\mathrm{b}}$ & $1.124^{\mathrm{d}}$ \\
$\mathrm{NP}$ & $0.997^{\mathrm{b}}$ & $0.986^{\mathrm{bc}}$ & $0.883^{\mathrm{b}}$ & $1.332^{\mathrm{b}}$ \\
$\mathrm{NK}$ & $0.722^{\mathrm{d}}$ & $0.907^{\mathrm{cd}}$ & $0.843^{\mathrm{c}}$ & $0.862^{\mathrm{e}}$ \\
$\mathrm{NPK}$ & $0.960^{\mathrm{b}}$ & $1.081^{\mathrm{b}}$ & $1.131^{\mathrm{b}}$ & $1.451^{\mathrm{c}}$ \\
$\mathrm{NPK}+\mathrm{Si}$ & $1.375^{\mathrm{a}}$ & $0.966^{\mathrm{c}}$ & $1.153^{\mathrm{b}}$ & $1.666^{\mathrm{b}}$ \\
$\mathrm{NPK}+$ Compost & $1.268^{\mathrm{a}}$ & $1.407^{\mathrm{a}}$ & $1.400^{\mathrm{a}}$ & $2.214^{\mathrm{a}}$ \\
F-value & $* * * *$ & $* * *$ & $* * *$ & $* * *$ \\
Threshold & 1.000 & 1.000 & 1.000 & 1.300 \\
CV(\%) & 23.3 & 19.7 & 25.4 & 25.4 \\
\hline
\end{tabular}

*Corresponding author : Phone: +82312900335, Fax: +85312900208, Email: chlee915@gmail.com

${ }^{\S}$ Acknowledgement: This study was supported by 2013 Postdoctoral Fellowship of National Academy Agricultural Science (PJ008598032013),

Rural Development Administration, Republic of Korea. 


\section{Introduction}

토양비옥도는 적절한 작물생육에 필요한 양분을 공급할 수 있는 능력을 말한다. 작물은 최적의 생육 및 생산성을 위해 토 양에서 필요한 양분을 흡수하지만, 집약농업에서 비료의 고투 입은 작물생산성 악화와 환경적 문제를 초래하며 (Cai and Smith, 1994; Ellis and Wang, 1997), 토양탄소 함량의 감소 로 토양질 및 토양생산성이 감소하기도 한다. (Li et al., 2010; Silveira et al., 2008). 따라서 적절한 비료사용에 의한 토양 비옥도 관리는 작물의 지속성과 환경보전을 위한 합리적인 방 안이 될 수 있다.

토양질은 지속적인 작물생산, 환경보전, 생태계 안정성에 대한 토양 기능의 용량으로 정의된다 (Larson and Pierce, 1994). 토양질을 통해 작물생산성과 농업생태계의 안정성을 높일 수 있기 때문에 합리적인 토양비옥도 관리에 유용한 수단 이 된다 (Doran and Parkin, 1994; Karlen and Stott., 1994). Gomez et al. (1996)는 경종방식이 다른 On-farming 에서 토양질 인자로 벼 생산 지속성을 평가하였고, Hussain et al. (1999)은 토지 이용형태에 따른 지속성 변화를 토양질 인 자로 평가하였다. 또한 Kang et al. (2005) 토양비옥도와 작 물생산성에 관련된 토양특성을 토양질 인자로 사용하여 논토 양에 화학비료와 유기물의 시용이 작물 지속성에 미치는 영향 을 평가하였다. 따라서 다양한 토양비옥도 관리에 있어 토양질 개념은 작물 지속성을 평가하는데 유용한 수단이 될 수 있다.

농경지의 지속성은 식량 확보와 생산자의 경제적 이익으로 직결되기 때문에 이것은 농업생태계의 안정성보다 많은 관심 을 받고 있다. 화학비료 장기 시용으로 의해 토양유기물 감소 및 양분불균형을 초래하며 벼의 지속성을 감소시킨다 (Singh and Singh, 1995; Yadav, 1998). 그러나 Lee et al. (2008)은 논토양에 지속적인 화학비료 시용이 벼 수량을 감소시키지 않 는다고 보고하였고, Zhen et al. (2006)은 화학비료 중 질소와 작물 수량과의 관계를 보고하였는데, 매년 $16 \mathrm{~kg} \mathrm{ha}^{-1}$ 의 질소 시비량을 증가함에 따라 밀과 옥수수의 평균 수량은 1967년 $2036 \mathrm{~kg} \mathrm{ha}^{-1}$ 에서 2000년 $6808 \mathrm{~kg} \mathrm{ha}^{-1}$ 으로 매년 $207 \mathrm{~kg}$ $\mathrm{ha}^{-1}$ 의 수량이 증가되어 작물 지속성을 위해 화학비료 시용이 중요하다고 강조하였다. 또한 많은 선행연구에서 화학비료 시 용은 근권의 작물체량 증진 및 토양 탄소 공급의 효과 때문에 토양특성 발달과 탄소저장 효과가 있다 (Gong et al., 2009; Li et al., 2010; Potter et al., 1998; Rudrappa et al., 2006). 그러나 토양비옥도 및 작물 지속성에 대한 화학비료 시 용 효과에 대한 연구는 거의 없는 실정으로 이에 대한 합리적 인 평가가 필요하다.

본 연구는 화학비료의 장기시용에 따른 벼 지속성을 평가하 고자 42년 동안 화학비료를 시용한 논토양에 토양화학적 특성, 미생물활성, 양분흡수와 생산성을 조사하여 논토양의 지속성 을 이용하였고, 이를 통해 지속적인 생산성을 위한 합리적인
시비방안을 모색하고자 하였다.

\section{Materials and Methods}

포장 및 시비관리 장기포장은 1967년 국립식량과학원 기능성 작물부내 설치되어 현재까지 관리되고 있다. 토양통은 미사질양토 그리고 배수약간 불량의 평택통이다. 시험 처리구 는 난괴법 3 반복으로 배치되었다. 질소시비는 벼 수량에 결정 적인 역할을 하기 때문에 본 연구에서 control, N, NP, NK, $\mathrm{NPK}, \mathrm{NPK}+\mathrm{Si}, \mathrm{NPK}+$ Compost와 같이 질소중심으로 총 7 개 의 처리구를 구성하였다. 시비관리는 1967-1972년까지 N- $\mathrm{P}_{2} \mathrm{O}_{5}$ $-\mathrm{K}_{2} \mathrm{O}=120-80-80 \mathrm{~kg} \mathrm{ha}^{-1}$ 으로, 1977년 이후부터는 150100-100 kg ha ${ }^{-1}$ 로 현재까지 시용하고 있다. 이때 질소는 요 소, 인산은 용성인비, 가리는 염화가리를 시용하였으며, 퇴비 는 볏짚퇴비로 매년 $10 \mathrm{Mg} \mathrm{ha}^{-1}$ 을 시용하였다. 규산처리구는 1981 년에 설치되었고, 벼 이앙 30 일 전에 분상질 규산 비료는 매년 $500 \mathrm{~kg} \mathrm{ha}^{-1}$ 을 시용하였다. 기비는 질소, 인산, 가리 시 용량의 $50,100,70 \%$ 를 시용하였고, 추비는 분얼기에 질소 $20 \%$ 를, 출수기에 질소와 가리를 각각 $30 \%$ 시용하였다. 벼 재 배에 사용된 벼 품종은 총 5 개로 다음과 같다: 1967년-1971 년 ‘팔광', 1972년-1975년 '밀성', 1975년-1986년 ‘팔공', 1987 년-1993년 '화남', 1994년부터 현재까지 '화삼.

토양 분석 $\quad 42$ 년차 (2008년)에 벼 수확기에 0- $15 \mathrm{~cm}$ 깊 이로 벼 수확기 표층토를 채취하였다. 이때 일부분은 풍건한 다음 $2 \mathrm{~mm}$ 체에 통과시켜 토양 분석에 이용하였고, 나머지 토 양시료는 $4^{\circ} \mathrm{C}$ 에 냉장 보관하여 microbial biomass와 효소활 성을 측정하였다. 토양 $\mathrm{pH}$ 는 $1: 5$ 법, 전탄소 $(\mathrm{TC})$ 와 전질소 (TN) 함량은 CNS 원소분석기로 측정하였고 (Leco, USA), 유 효인산은 Lancaster 법, 치환성 양이온은 $1 \mathrm{~N} \mathrm{NH}_{4} \mathrm{OAc}$ 법 (pH 7.0)으로 침출 및 여과하여 ICP 분석하였다. 양이온치환 용량(CEC)은 Schofeild (1949)법으로 측정하였다. 암모니아태 질소 함량은 습토 $10 \mathrm{~g}$ 에 $2 \mathrm{M} \mathrm{KCl}$ 용액으로 침출하여 질소자 동분석장치로 측정하였다 (NAAS, 2000). 유효규산 함량은 $1 \mathrm{~N}$ $\mathrm{Na}$-acetate $(\mathrm{pH} 4.0)$ 용액으로 $60^{\circ} \mathrm{C}$ 에서 90 분간 진탕 여과하여 UV-spectrophotometer로 측정하였다 (NAAS, 2000).

Microbial biomass $\mathrm{C}$ and $\mathrm{N}$ 함량은 chloroform fumigation 법에 의해 측정하였다 (Vance et al., 1987; Ross, 1992). 이 때 각각의 함량 조사는 2 단계로 나누어 실시하였다. 1 단계는 건토기준 $10 \mathrm{~g}$ 의 습토를 진공 데시케이터 내에서 24 시간 동안 $\mathrm{CH}_{3} \mathrm{Cl}$ 로 훈증 처리하였다. 훈증된 토양을 $0.5 \mathrm{M} \mathrm{K}_{2} \mathrm{SO}_{4}$ 용액 으로 진탕 및 여과하였다. 그리고 2 단계에서 훈증하지 않은 습 토를 $0.5 \mathrm{M} \mathrm{K}_{2} \mathrm{SO}_{4}$ 용액으로 진탕 및 여과하였다. 각각의 여과 된 용액은 Total organic carbon and Nitrogen (TOC-TN) 분석기로 유기탄소와 전질소 함량을 측정하였고, microbial biomass C와 N 함량은 (훈증-비훈증)/k 식으로 산정하였다. 
이때 $\mathrm{k}$ 는 microbial biomass C에 0.45 를, microbial biomass N에 0.54를 각각 적용하였다 (Jenkinson, 1988; Sparling and West,1988). Potential mineralizable nitrogen (PMN) 은 건조기준 $20 \mathrm{~g}$ 의 습토를 혐기성 조건으로 $30^{\circ} \mathrm{C}$ 에서 14 일 동안 배양하였다. 이때 $\mathrm{PMN}$ 함량은 배양 전·후의 습토를 $2 \mathrm{M}$ $\mathrm{KCl}$ 로 진탕 및 여과하였고, 여과된 용액 중 $\mathrm{NH}_{4}{ }^{+}-\mathrm{N}$ 농도 차 이로 산정하였다 (Keeney, 1982). Dehydrogenase 활성은 triphenyl formazan (TPF)를 이용하였고, 24 시간후 2,3,5-tri phenyl tetrazolium chloride (TTC) 농도를 분석하였다 (Casida et al., 1964). Acid phosphatase 활성은 Eivazi and Tabatabai (1977) 법으로 측정하였다.

식물체 분석 벼는 $3.3 \mathrm{~m}^{2}$ 에서 수확하여 $70{ }^{\circ} \mathrm{C}$ 에서 72 시간 동안 건조한 후, 정조와 볏짚 무게를 산정하였다. 이때 식물체 양분흡수량을 산정하고자 정조와 볏짚을 각각 곱게 분 쇄하여 식물체 분석을 실시하였다. 질소 함량은 conc. $\mathrm{H}_{2} \mathrm{SO}_{4}$ 로 분해한 후에 킬달장치로 측정하였다. $\mathrm{P}, \mathrm{K}, \mathrm{Ca}$, 그리고, $\mathrm{Mg}$ 함량은 ternary solution $\left(\mathrm{HNO}_{3}: \mathrm{H}_{2} \mathrm{SO}_{4}: \mathrm{HClO}_{4}, 10: 1\right.$ : $4 \mathrm{v} / \mathrm{v}$ )을 이용하여 분해하여 Vanadate법과 ICP로 측정하였 고, 조규산 함량은 회화법을 이용하였다 (NAAS, 2000).

지속성 지수 장기비료 시용에 따른 논토양의 지속성 평 가는 Kang et al. (2005)에 의해 제안된 방법을 이용하였다. 지속성 지수화를 위해서는 사용된 분석항목은 총 23 개이다. 이때 치환성 $\mathrm{Na}$ 함량은 처리간 통계적 유의차가 없기 때문에 양분지수 계산에서 제외하였다. 양분 지수는 $\mathrm{pH}$, Total C, Total N, NH4 $-\mathrm{N}$, Av. $\mathrm{P}_{2} \mathrm{O}_{5}, \mathrm{Ex} . \mathrm{K}, \mathrm{Ex} . \mathrm{Ca}, \mathrm{Ex} . \mathrm{Mg}, \mathrm{CEC}$, 그리고 $\mathrm{Av} . \mathrm{SiO}_{2}$ 함량과 같이 10 개를, 미생물 지수는 microbial biomass C와 N, PMN, dehydrogenase, 그리고 acid phosphatase 와 같이 5 개를, 생산성 지수는 Biomass, N, P, K, $\mathrm{Ca}, \mathrm{Mg}$, 그리고 $\mathrm{SiO}_{2}$ 와 같이 7 개의 변수를 이용하여 각각의
지수를 산정하였다. 지수성 지수는 총 두 단계를 걸쳐 구하는 데, 첫째 아래와 같이 각 분석 항목의 값을 지수로 변환하였다.

$$
\mathrm{I}=\mathrm{A} / \text { Threshold }
$$

여기서, Threshold는 각 분석항목의 값을 평균한 것이며, A 는 각 분석항목의 값을 의미한다. 이 두 값을 이용하여 각 항 목별 지수값 (I)를 구하였다. 그러나 벼 체량의 threshold는 정 조와 볏짚 건물의 합에 1.2 를 곱한 값을 평균하였고, 각 항목 의 지수값은 위와 동일한 방법으로 산정하였다 (Gomea et al., 1996).

지속성 지수의 산정을 위한 두 번째는 양분지수, 미생물 활 성 지수, 그리고 작물지수를 구하는 것이다. 양분지수는 분석 항목 10 개, 미생물 활성 지수는 5 개, 작물지수는 7 개에 대한 각 지수값의 평균이다. 이를 이용하여 아래와 같이 지속성 지 수를 산정하였다.

Sustainability Index $(\mathrm{SI})=0.433 \times(\mathrm{ab}+\mathrm{bc}+\mathrm{ac})$

이때 $\mathrm{a}$ 는 양분지수, $\mathrm{b}$ 는 미생물 활성지수, $\mathrm{c}$ 는 작물 지수이 다. 지속성을 의미하는 최소 SI 값은 1.300 으로 정의된다.

통계처리 데이터 분석은 SAS 프로그램으로 변이계수 및 ANOVA 분석을 실시하였고, 유의수준 5\%로 Duncan 검정으로 처리간 평균을 비교하였다. 지속성 지수와 정조수량과의 모델 을 검정하기 위해 $5 \%$ 유의수준에서 회귀분석을 실시하였다.

\section{Results and Discussion}

토양 화학적 특성 논토양에 장기간 화학비료의 시비는 토양화학적 특성에 영향을 끼쳤다 (Table 1). 토양 $\mathrm{pH}$ 는 화학

Table 1. Chemical properties related to nutrient index in paddy soil after fertilization for 41 years.

\begin{tabular}{|c|c|c|c|c|c|c|c|c|c|c|c|}
\hline \multirow{2}{*}{ Treatments } & \multirow{2}{*}{$\mathrm{pH}$} & \multirow{2}{*}{$\mathrm{T}-\mathrm{C}$} & \multirow{2}{*}{$\mathrm{T}-\mathrm{N}$} & \multirow{2}{*}{$\mathrm{NH}_{4}^{+}-\mathrm{N}$} & \multirow{2}{*}{ Av. $\mathrm{P}_{2} \mathrm{O}_{5}$} & \multicolumn{4}{|c|}{ Ex.cation } & \multirow{2}{*}{ CEC } & \multirow{2}{*}{ Av. $\mathrm{SiO}_{2}$} \\
\hline & & & & & & $\mathrm{K}$ & $\mathrm{Ca}$ & $\mathrm{Mg}$ & $\mathrm{Na}$ & & \\
\hline & $(1: 5)$ & \multicolumn{2}{|c|}{---- $\mathrm{g} \mathrm{kg}^{-1}$----- } & \multicolumn{2}{|c|}{---- $\mathrm{mg} \mathrm{kg}^{-1}$} & 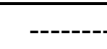 & -- $\mathrm{cmo}$ & $\mathrm{kg}^{-1}$ & $\begin{array}{c}---- \\
-\cdots-\end{array}$ & $\mathrm{cmol} \mathrm{kg}^{-1}$ & $\mathrm{mg} \mathrm{kg}{ }^{-1}$ \\
\hline Control & $5.39^{\mathrm{b}}$ & $14.9^{\mathrm{c}}$ & $2.00^{\mathrm{ab}}$ & $11.7^{\mathrm{c}}$ & $29^{\mathrm{cd}}$ & $0.11^{\mathrm{c}}$ & $3.93^{\mathrm{c}}$ & $0.83^{\mathrm{b}}$ & 0.27 & $9.9^{\mathrm{c}}$ & $69^{\mathrm{b}}$ \\
\hline $\mathrm{N}$ & $5.33^{\mathrm{b}}$ & $16.8^{\mathrm{bc}}$ & $2.19^{\mathrm{ab}}$ & $14.5^{\mathrm{ab}}$ & $33^{\mathrm{c}}$ & $0.20^{\mathrm{b}}$ & $4.48^{\mathrm{bc}}$ & $0.95^{\mathrm{ab}}$ & 0.26 & $10.8^{\mathrm{bc}}$ & $62^{\mathrm{b}}$ \\
\hline NP & $5.47^{\mathrm{b}}$ & $16.0^{\mathrm{bc}}$ & $1.99^{\mathrm{ab}}$ & $15.4^{\mathrm{a}}$ & $149 \mathrm{~b}$ & $0.13^{\mathrm{c}}$ & $4.57^{\mathrm{bc}}$ & $1.12^{\mathrm{ab}}$ & 0.27 & $12.4^{\mathrm{ab}}$ & $76^{\mathrm{b}}$ \\
\hline NK & $5.30^{\mathrm{b}}$ & $15.8^{\mathrm{bc}}$ & $1.94^{\mathrm{b}}$ & $12.6^{\mathrm{bc}}$ & $15^{\mathrm{d}}$ & $0.10^{\mathrm{c}}$ & $2.46^{\mathrm{d}}$ & $0.49^{\mathrm{c}}$ & 0.27 & $11.6^{\mathrm{bc}}$ & $58^{\mathrm{b}}$ \\
\hline NPK & $5.43^{\mathrm{b}}$ & $16.5^{\mathrm{bc}}$ & $1.94^{\mathrm{b}}$ & $12.1^{\mathrm{bc}}$ & $153^{\mathrm{b}}$ & $0.16^{\mathrm{bc}}$ & $4.34^{\mathrm{bc}}$ & $1.05^{\mathrm{ab}}$ & 0.27 & $10.7^{\mathrm{bc}}$ & $73_{b}$ \\
\hline $\mathrm{NPK}+\mathrm{Si}$ & $5.91^{\mathrm{a}}$ & $17.1^{\mathrm{b}}$ & $1.93^{\mathrm{b}}$ & $12.7^{\mathrm{bc}}$ & $148^{\mathrm{b}}$ & $0.16^{\mathrm{bc}}$ & $6.51^{\mathrm{a}}$ & $1.12^{\mathrm{ab}}$ & 0.26 & $12.2^{\mathrm{ab}}$ & $646^{\mathrm{a}}$ \\
\hline NPK + Compost & $5.43^{\mathrm{b}}$ & $25.3^{\mathrm{a}}$ & $2.31^{\mathrm{a}}$ & $14.5^{\mathrm{ab}}$ & $190^{\mathrm{a}}$ & $0.43^{\mathrm{a}}$ & $5.35^{\mathrm{ab}}$ & $1.19^{\mathrm{a}}$ & 0.28 & $13.4^{\mathrm{a}}$ & $85^{\mathrm{b}}$ \\
\hline$F$-value & $* *$ & $* * *$ & $*$ & $*$ & $* * *$ & $* * *$ & $* * *$ & $* * *$ & ns & $* *$ & $* * *$ \\
\hline Threshold & 5.46 & 17.45 & 2.04 & 13.4 & 102 & 0.18 & 4.52 & 0.96 & 0.27 & 11.6 & 152.7 \\
\hline $\mathrm{CV}(\%)$ & 4.3 & 19.8 & 9.8 & 13.4 & 68.5 & 60.4 & 29.5 & 27.5 & 5.6 & 11.7 & 137 \\
\hline
\end{tabular}

Note) $\mathrm{CV}$ means coefficient of variation. 
비료 및 퇴비시용으로 처리간 뚜렷한 차이를 나타내지 않았으 나, 규산질 비료는 $\mathrm{Ca}$ 를 다량함유하기 때문에 $\mathrm{NPK}+\mathrm{Si}$ 처리구 는 타 처리구에 비해 토양 $\mathrm{pH}$ 가 크게 개선되었다 (Lee et al., 2005). 화학비료 $(\mathrm{N}, \mathrm{NP}, \mathrm{NK}, \mathrm{NPK}, \mathrm{NPK}+\mathrm{Si})$ 장기 시용에 의한 토양중 전탄소 $(\mathrm{TC})$ 함량은 무시용구에 비해 증가되었다. 그리고 화학비료 단독보다는 규산질비료와 퇴비 혼용시용이 토양 중 TC 함량을 증가시켰다 (Table 1). 토양 TC 함량은 농 경지로 유입되는 탄소 투입량, 조성 및 $\mathrm{C} / \mathrm{N}$ 율에 영향을 받는 다 (Khalil et al., 2005; Trinsoutrot et al., 2000). Kumar and Yadav (1995)은 벼-밀 작부체계에서 화학비료 (NPK) 및 $\mathrm{FYM}$ 의 시용에 의해 토양의 전탄소 함량은 증가된다고 보고하 였는데, 화학비료 구의 $\mathrm{TC}$ 함량의 증가는 벼 근권체량 증가에 서 기인된 것으로 판단된다.

전질소 $(\mathrm{TC})$ 함량은 $\mathrm{NPK}+$ Compost 처리구를 제외한 전처 리구에서 통계적 유의차가 없었고, 가용성 $\mathrm{NH}_{4}-\mathrm{N}$ 함량은 무 비구에 비해 화학비료구에서 다소 높아졌다. 화학비료 질소단 용 $(\mathrm{N})$ 에 P 첨가는 $\mathrm{TN}$ 함량에는 영향이, 가용성 $\mathrm{NH}_{4}-\mathrm{N}$ 함량 증가 시켰다. 그러나 $\mathrm{N}$ 단용에 $\mathrm{K}$ 첨가는 $\mathrm{TN}$ 과 $\mathrm{NH}_{4}-\mathrm{N}$ 함량을 동시에 감소시켰다. 특히 지속적인 인산질 비료 시용은 토양 중 유효인산 함량 증가와 더불어 치환성 $\mathrm{Ca}$ 와 $\mathrm{Mg}$ 함량에 영향 을 주었다. 왜냐하면 $\mathrm{NK}$ 처리구는 치환성 $\mathrm{Ca}$ 와 $\mathrm{Mg}$ 함량이 처 리구 중 가장 낮은 반면에 $\mathrm{NP}$ 처리구는 $\mathrm{NPK}$ 에 비해 치환성 $\mathrm{Ca}$ 와 $\mathrm{Mg}$ 가 차이를 나타내지 않기 때문이다. 치환성 $\mathrm{K}$ 함량은 $\mathrm{N}, \mathrm{K}$, 규산, 그리고 화학비료와 퇴비에 의해서 증가되었다. $\mathrm{NPK}+\mathrm{Si}$ 처리구를 제외한 전처리구의 유효규산 함량은 58-82 $\mathrm{mg} \mathrm{kg}^{-1}$ 인 반면에 $\mathrm{NPK}+\mathrm{Si}$ 구에서 $\mathrm{Av} \cdot \mathrm{SiO}_{2}$ 함량은 $646 \mathrm{mg}$ $\mathrm{kg}^{-1}$ 이었다. 이는 매년 규산질 비료를 $500 \mathrm{~kg} \mathrm{ha}^{-1}$ 시용한 결 과로 해석되며 토양 $\mathrm{pH}$ 와 치환성 $\mathrm{Ca}$ 함량 증가에 기여한 것으 로 사료된다 (Lee et al., 2005). 양이온치환용량 (CEC)은 TC 함량과 고도의 정의 상관관계를 나타내었다 $(\mathrm{p}<0.01)$.
Microbial biomass와 효소활성 토양의 생물학적 특성 중 미생물과 효소 활성은 토양질을 평가하는 중요한 인자로 이 용된다 (Nannipieri et al., 1990; 2002). 또한 토양 중 유기 물은 미생물에 의해 분해 및 무기화로 작물에 양분을 공급할 수있다 (Govaerts et al., 2006; Imaz et al., 2010, Parisi et al., 2005). Table 2와 같이, Microbial biomass C와 N, 그 리고 효소활성은 NPK+Compost 시용에 의해 가장 큰 영향을 받았다. 일반적으로 토양내 microbial biomass 및 효성활성은 토양 탄소함량, 기질 조성, 그리고 토양 $\mathrm{pH}$ 와 밀접한 관계가 있는데 (Hussain et al., 1999; Imaz et al., 2010), NPK+Si 처리구를 제외한 Microbial biomass와 효소활성은 토양의 TC 함량과 정의상관관계를 나타내었다 $(\mathrm{p}\langle 0.01) . \mathrm{NPK}+\mathrm{Si}$ 의 $\mathrm{TC}$ 함량은 $17.1 \mathrm{~g} \mathrm{~kg}^{-1}$ 으로 NPK에 비해 뚜렷한 차이가 없었으나, microbial biomass와 효소활성은 NPK에 비해 낮았다. 규산질 비료에 함유된 철과 벼 생육기간 중 뿌리에서 분비되는 페놀화 합물은 미생물 활성을 저해시킬 수 있다 (Ma et al., 1989; Lee et al., 2005, Lee et al., 2012). 이러한 작용이 규산처리구의 microbial biomass, dehydrogenase 및 acid phosphatase 활성에 영향을 미친 것으로 사료된다. NK구의 potential mineralizable $\mathrm{N}(\mathrm{PMN})$ 은 $6.8 \mathrm{mg} \mathrm{kg}^{-1}$ 으로 control에 비해 약 $30 \%$ 감소되어 $\mathrm{PMN}$ 을 위해 인산질 비료의 시용이 필요한 것으로 판단된다.

벼 생산성 및 양분흡수 비료의 시비형태는 화학· 생물 학적 특성 뿐만 아니라 벼 체량과 양분흡수에 영향을 미쳤다 (Table 3). 벼 체량은 NPK+Compost가 $17.3 \mathrm{Mg} \mathrm{ha}^{-1}$ 으로 가 장 높았고, $\mathrm{NPK}+\mathrm{Si}>\mathrm{NPK}>\mathrm{N}>\mathrm{NP}>\mathrm{NK}>$ Control 순으 로 낮아지는 경향을 보였다. NP와 NK구에서 $\mathrm{P}$ 와 $\mathrm{K}$ 의 흡수량 은 NPK에 비해 각각 낮았고, 벼 체량은 각각 19.0 과 $10.6 \%$ 감소되었다. 이는 벼에 $\mathrm{P}$ 와 $\mathrm{K}$ 결핍으로 광합성, 동화작용이 저해된 결과로 사료된다. 그러나 질소단용구에서 $\mathrm{K}$ 흡수량은

Table 2. Biological properties related to microbial activity index in paddy soil after fertilization for 41 years.

\begin{tabular}{|c|c|c|c|c|c|}
\hline \multirow{2}{*}{ Treatments } & \multicolumn{2}{|c|}{ Microbial biomass } & \multirow{2}{*}{ Potential mineralizable $\mathrm{N}$} & \multirow{2}{*}{ Dehydrogenase } & \multirow{2}{*}{ Acid phosphates } \\
\hline & Carbon & Nitrogen & & & \\
\hline & ----- & -------- & - $\mathrm{mg} \mathrm{kg}^{-1} \mathrm{~d}^{-1}$ & $\mathrm{~g} \mathrm{~kg}^{-1}$ & $\mathrm{mg} \mathrm{kg}^{-1} 24 \mathrm{hr}^{-1}$ \\
\hline Control & $250.6^{\mathrm{d}}$ & $33.6^{\mathrm{c}}$ & $9.7^{\mathrm{bcd}}$ & $49.0^{\mathrm{d}}$ & $173.3^{\mathrm{bc}}$ \\
\hline $\mathrm{N}$ & $262.0^{\mathrm{d}}$ & $32.0^{\mathrm{c}}$ & $10.7^{\mathrm{bc}}$ & $49.9^{\mathrm{d}}$ & $167.4^{\mathrm{bc}}$ \\
\hline NP & $367.8^{\mathrm{ab}}$ & $47.2^{\mathrm{b}}$ & $10.3^{\mathrm{bcd}}$ & $57.0^{\mathrm{cd}}$ & $172.6^{\mathrm{bc}}$ \\
\hline NK & $346.7^{\mathrm{bc}}$ & $40.6^{\mathrm{bc}}$ & $6.8^{\mathrm{d}}$ & $64.9^{\mathrm{bc}}$ & $176.3^{\mathrm{bc}}$ \\
\hline NPK & $392.8^{\mathrm{ab}}$ & $50.5^{\mathrm{b}}$ & $9.4^{\mathrm{cd}}$ & $71.4^{\mathrm{b}}$ & $208.0^{\mathrm{ab}}$ \\
\hline $\mathrm{NPK}+\mathrm{Si}$ & $286.7^{\mathrm{cd}}$ & $43.0^{\mathrm{bc}}$ & $13.4^{\mathrm{ab}}$ & $59.5^{\mathrm{c}}$ & $157.9^{\mathrm{c}}$ \\
\hline NPK +Compost & $422.1^{\mathrm{a}}$ & $66.2^{\mathrm{a}}$ & $15.3^{\mathrm{a}}$ & $104.3^{\mathrm{a}}$ & $233.1^{\mathrm{a}}$ \\
\hline F-value & $* * *$ & $* * *$ & $* * *$ & $* * *$ & $*$ \\
\hline Threshold & 332.7 & 44.7 & 10.8 & 65.1 & 184.1 \\
\hline $\mathrm{CV}(\%)$ & 21.1 & 28.0 & 28.9 & 28.4 & 17.3 \\
\hline
\end{tabular}

Note) CV means coefficient of variation. 
Table 3. Phytomass and nutrient uptake related to productivity index in paddy soil after fertilization for 41 years.

\begin{tabular}{|c|c|c|c|c|c|c|c|}
\hline \multirow{2}{*}{ Treatments } & \multirow{2}{*}{ Phyto-biomass - } & \multicolumn{6}{|c|}{ Nutrient Uptake } \\
\hline & & $\mathrm{N}$ & $\mathrm{P}$ & $\mathrm{K}$ & $\mathrm{Ca}$ & $\mathrm{Mg}$ & $\mathrm{SiO}_{2}$ \\
\hline & $\mathrm{Mg} \mathrm{ha}^{-1}$ & \multicolumn{6}{|c|}{ 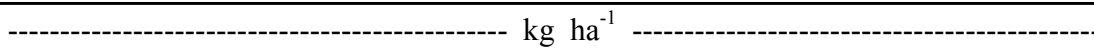 } \\
\hline Control & $8.3^{\mathrm{e}}$ & $43.6^{\mathrm{d}}$ & $12.0^{\mathrm{c}}$ & $52.7^{\mathrm{d}}$ & $16.4^{\mathrm{c}}$ & $7.4^{\mathrm{d}}$ & $126.0^{\mathrm{c}}$ \\
\hline $\mathrm{N}$ & $13.9^{\mathrm{bc}}$ & $109.9^{\mathrm{b}}$ & $24.1^{\mathrm{b}}$ & $91.4^{\mathrm{c}}$ & $24.6^{\mathrm{b}}$ & $15.8^{\mathrm{b}}$ & $127.1^{\mathrm{c}}$ \\
\hline NP & $11.9^{\mathrm{d}}$ & $83.4^{\mathrm{c}}$ & $21.7^{\mathrm{b}}$ & $64.1^{\mathrm{d}}$ & $22.2^{\mathrm{b}}$ & $14.5^{\mathrm{b}}$ & $148.9^{\mathrm{c}}$ \\
\hline NK & $12.7^{\mathrm{cd}}$ & $77.8^{\mathrm{c}}$ & $12.7^{\mathrm{c}}$ & $96.6^{\mathrm{c}}$ & $24.4^{\mathrm{b}}$ & $11.7^{\mathrm{c}}$ & $134.7^{\mathrm{c}}$ \\
\hline NPK & $14.2^{\mathrm{b}}$ & $102.8^{\mathrm{b}}$ & $24.1^{\mathrm{b}}$ & $115.5^{\mathrm{b}}$ & $28.4^{\mathrm{a}}$ & $15.9^{\mathrm{b}}$ & $218.5^{\mathrm{b}}$ \\
\hline $\mathrm{NPK}+\mathrm{Si}$ & $15.2^{\mathrm{b}}$ & $105.1^{\mathrm{b}}$ & $23.0^{\mathrm{b}}$ & $119.2^{\mathrm{b}}$ & $22.9^{\mathrm{b}}$ & $16.6^{\mathrm{b}}$ & $266.2^{\mathrm{a}}$ \\
\hline NPK + Compost & $17.3^{\mathrm{a}}$ & $126.0^{\mathrm{a}}$ & $32.1^{\mathrm{a}}$ & $170.7^{\mathrm{a}}$ & $28.1_{\mathrm{a}}$ & $19.3^{\mathrm{a}}$ & $267.9^{\mathrm{a}}$ \\
\hline F-value & $* * *$ & $* * *$ & $* * *$ & $* * *$ & $* * *$ & $* * *$ & $* * *$ \\
\hline Threshold & 13.3 & 92.6 & 21.4 & 101.5 & 23.8 & 14.5 & 184.2 \\
\hline $\mathrm{CV}(\%)$ & 20.5 & 28.1 & 32.5 & 37.4 & 17.4 & 26.8 & 34.1 \\
\hline
\end{tabular}

Note) Phyto-mass was summed the weight of grain yield and straw. CV means coefficient of variation.

Table 4. Sustainable index of paddy soil after fertilization for 42 years.

\begin{tabular}{|c|c|c|c|c|}
\hline Treatments & $\begin{array}{c}\text { Nutrient } \\
\text { index }\end{array}$ & $\begin{array}{c}\text { Microbiological } \\
\text { index }\end{array}$ & $\begin{array}{l}\text { Crop } \\
\text { index }\end{array}$ & $\begin{array}{c}\text { Sustainability } \\
\text { index }\end{array}$ \\
\hline Control & $0.791^{\mathrm{bc}}$ & $0.819^{\mathrm{d}}$ & $0.579^{\mathrm{d}}$ & $0.696^{\mathrm{f}}$ \\
\hline $\mathrm{N}$ & $0.888^{\mathrm{bc}}$ & $0.833^{d}$ & $1.010^{\mathrm{b}}$ & $1.124^{\mathrm{d}}$ \\
\hline NP & $0.997^{\mathrm{b}}$ & $0.986^{\mathrm{bc}}$ & $0.883^{\mathrm{b}}$ & $1.332^{\mathrm{b}}$ \\
\hline NK & $0.722^{\mathrm{d}}$ & $0.907^{\mathrm{cd}}$ & $0.843^{\mathrm{c}}$ & $0.862^{\mathrm{e}}$ \\
\hline NPK & $0.960^{\mathrm{b}}$ & $1.081^{\mathrm{b}}$ & $1.131^{\mathrm{b}}$ & $1.451^{\mathrm{c}}$ \\
\hline $\mathrm{NPK}+\mathrm{Si}$ & $1.375^{\mathrm{a}}$ & $0.966^{\mathrm{c}}$ & $1.153^{\mathrm{b}}$ & $1.666^{\mathrm{b}}$ \\
\hline NPK + Compost & $1.268^{\mathrm{a}}$ & $1.407^{\mathrm{a}}$ & $1.400^{\mathrm{a}}$ & $2.214^{\mathrm{a}}$ \\
\hline F-value & $* * *$ & $* * *$ & $* * *$ & $* * *$ \\
\hline Threshold & 1.000 & 1.000 & 1.000 & 1.300 \\
\hline $\mathrm{CV}(\%)$ & 23.3 & 19.7 & 25.4 & 25.4 \\
\hline
\end{tabular}

Note) CV means coefficient of variation.

$91.4 \mathrm{~kg} \mathrm{ha}^{-1}$ 로 NPK에 비해 $26 \%$ 낮았지만, 벼 체량은 약 $3 \%$ 미만으로 NPK와 뚜렷한 차이가 없었다. 규산을 NPK와 함께 시용함으로써 $\mathrm{N}, \mathrm{K}, \mathrm{SiO}^{2}$ 의 흡수가 증가되었고, $\mathrm{NPK}$ 와 볏짚 퇴비를 혼용한 결과, 벼 체량과 양분흡수가 타 처리구에 비해 가장 높았다.

벼에 대한 규산 효과는 광합성과 질소이용 효율을 향상시키 고, 병충해와 도복저항성을 증가시키는 것으로 알려져 있다 (Yoshida et al. 1969; Lian, 1976; Takahashi et al., 1990). Table 3 에서 보듯이, $\mathrm{NPK}+\mathrm{Si}$ 구의 $\mathrm{SiO}_{2}$ 흡수량은 약 $266 \mathrm{~kg}$ $\mathrm{ha}^{-1}$ 으로 NPK구에 비해 약 $19 \%$ 향상되었다. 이러한 결과는 사한다. 또한 벼 체량과 양분흡수량은 NPK와 더불어 추가적인 유기물에 영향을 받는 것으로 판단된다.

논토양의 지속성 지수 논토양의 지속성 지수를 산정하 고자 양분지수, 미생물지수, 작물 지수는 10 개의 화학적 특성, 6 개의 미생물체량과 효소활성, 5 개의 작물생산과 양분흡수 항
목을 이용하였다. 이때 치환성 나트륨은 처리간 차이가 없기 때문에 양분 지수 변환에서 제외하였다. Table 4 와 같이 논토 양의 지속성 지수는 NPK+Compost가 2.214으로 가장 높았다. 본 시험에 사용된 지속성 평가기법은 지속성을 나타내는 최소 값은 1.300 으로 정의되고 있다 (Kang et al., 2005). 유기물 의 시용이 없었던 $\mathrm{NP}, \mathrm{NPK}, \mathrm{NPK}+\mathrm{Si}$ 의 지속성 지수는 각각 $1.332,1.451,1.666$ 으로 논토양의 지속성은 인정되었지만, 미생물 지수보다는 양분과 작물지수에 의해 지속성 지수가 더 많은 영향을 받았다. 질소단용 $(\mathrm{N})$ 과 무인산 $(\mathrm{NK})$ 는 지속성 지수가 각각 $1.124,0.862$ 로 평가되었고, 특히 $\mathrm{NK}$ 는 양분지 수는 0.722 로 처리구 중 가장 낮았고, 작물지수는 0.843 으로 control을 제외하면 가장 낮은 지수의 값을 나타내기 때문에 논토양의 지속성은 인산질 비료의 시용이 필요하다는 것을 시 사하고 있다.

논토양의 지속성 지수를 이용하여 벼 정조수량과의 관계를 Fig. 1에 나타내었다. 두 변수 (지속성지수와 정조수량)의 회 


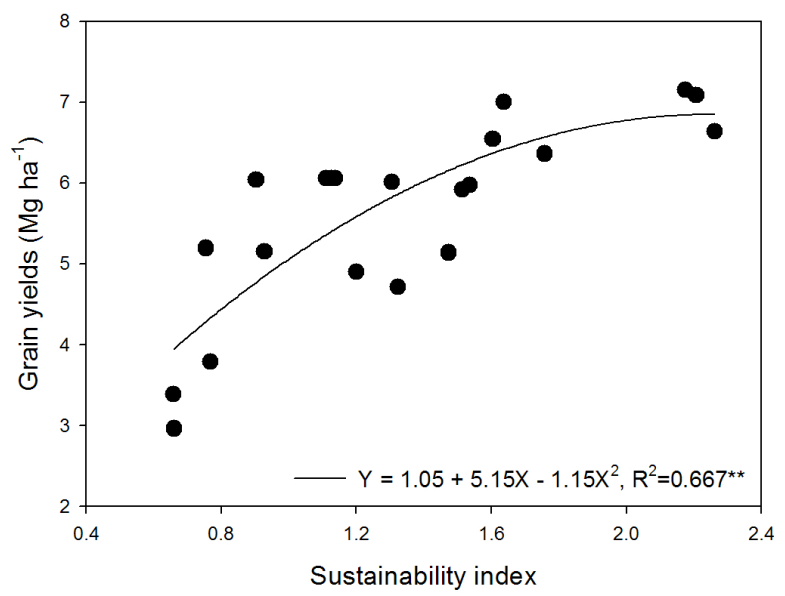

Fig. 1. Sustainable Relationship between grain yields and sustainability index under long-term fertilization in mono-rice cultivation.

귀식은 $\mathrm{Y}=1.05+5.15 \mathrm{X}-1.15 \mathrm{X}^{2}$ 으로 결정계수 $\left(\mathrm{R}^{2}=0.667^{* *}\right)$ 가 유의성을 가지고 있었고, 논토양의 지속성 지수가 2.000 이 상일 때 최대 정조수량을 나타내었다. 이상의 결과는 지속적인 $\mathrm{NP}, \mathrm{NPK}, \mathrm{NPK}+\mathrm{Si}$ 시용이 논토양 지속성을 감소시키지 않았 다. 그러나 벼 생산성을 고려한다면 화학비료와 유기물의 적절 한 혼합 시용이 논토양의 지속성 향상에 가장 합리적인 방안으 로 평가되었다.

\section{Conclusion}

벼 생산성을 지속시키는 합리적인 시비방안을 모색하고자 화학비료의 시용에 따른 논토양의 지속성을 평가하였다. 이를 위해 42 년 동안 동일비료를 시용한 장기시험포장에서 control, $\mathrm{N}, \mathrm{NP}, \mathrm{NK}, \mathrm{NPK}, \mathrm{NPK}+\mathrm{Si}, \mathrm{NPK}+$ Compost의 총 7 개 처리구 를 선발하였고, 양분지수, 미생물지수, 작물 지수를 이용하여 처리구간 지속성 지수를 비교하였다. 지속성 지수는 NPK+ Compost가 2.214으로 가장 높았다. 화학비료 처리구 중 NP, $\mathrm{NPK}, \mathrm{NPK}+\mathrm{Si}$ 의 지속성 지수는 각각 $1.332,1.451,1.666$ 으로 논토양의 지속성이 있었다. 그러나 질소단용 $(\mathrm{N})$ 과 무인산 $(\mathrm{NK})$ 는 지속성 지수가 각각 $1.124,0.862$ 로 지속성이 없었다. 이상으로 결과에서 벼 생산성과 지속성 향상을 위해서는 NPK 와 더불어 유기물 혼용이 가장 우수한 것으로 평가되었다.

\section{References}

Cai, Y.L, and B. Smith. 1994. Sustainability in Chinese agriculture: challenge and hope. Agri. Ecosys. Environ. 49: 279-288.

Casida, L.E., D.A. Klein, and T. Santoro. 1964. Soil dehydrogenase activity. Soil Sci 98:371-376.

Doran, J.W. and T.B. Parkin. 1994. Defining and assessing soil quality. p. 3-21. In J.W. Doran et al. (ed.) Defining soil quality for a sustainable environment. SSSA Spec. Publ. 35. SSSA and ASA, Madison, WI.

Ellis, E.C. and S.M. Wang. 1997. Sustainable traditional agriculture in the Taihu Lake Region of China. Agri. Ecosys. Environ. 61: 177-193.

Eivazi, F. and M.A. Tabatabai. 1977. Phosphatases in soils. Soil Biol. Biochem. 9:167-172.

Glover, J.D., J.P. Reganold, and P.K. Andrews. 2000. Systematic method for rating soil quality of conventional, organic, and integrated apple orchard in Washington State. Agric. Ecosyst. Environ. 80: 29-45.

Gomez, A.A., D.E.S. Kelly, J. K. Syers, K.J. Coughlan, and J.W. Doran. 1996. Measuring sustainability of agricultural systems at the farm level. In: Doran JW, Jones AJ (eds) Methods for assessing soil quality, pp. 401-410. Soil Sci Soc Am Spec Publ 49, Madison, WI, USA,

Hussain, I., K.R. Olson, M.M. Wander, and D.L. Karlen. 1999. Adaptation of soil quality indices and application to three tillage systems in southern Illinois. Soil Tillage Res. 50: 237-249.

Imaz, M.J., I.V.P. Bescansa, A. Enrique, O. Fernandez-Ugalde, and D.L. Karlen. 2010. Soil quality indicator response to tillage and residue management on semi-arid Mediterranean cropland. Soil Tillage Res. 107:17-25.

Jenkinson, D.S. 1988. Determination of microbial biomass carbon and nitrogen in soil. In: Wilson, J.R. (Ed.), Advances in Nitrogen Cycling in Agricultural Ecosystems, pp. 368-385. CAB International, Wallingford,

Kang, G.S., V. Beri., B.S. Sidhu, and O.P. Rupela. 2005. A new index to assess soil quality and sustainability of wheat-based cropping systems. Biol. Fertil. Soils. 41: 389-398.

Karlen, D.L. and D.E. Stott. 1994. A framework for evaluating physical and chemical indicators of soil quality. In: Doran, J.W., Coleman, D.C., Bezdicek, D.F., Stewart, B.A. (Eds.), Defining Soil Quality for a Sustainable Environment, pp. 53-72. SSSA Special Publication No. 35, ASA and SSSA, Madison, WI.

Keeney, D.R. 1982. Nitrogen-availability indices. In: Page AL, Miller RH, Keeney DR (eds) Methods in soil analysis - part 2,chemical and microbial properties, pp. 711-733. Soil Science Society of America Inc, Publisher, Madison, WI, USA.

Khalil, M.I., M.B. Hossain, and U. Schmidhalter. 2005. Carbon and nitrogen mineralization in different upland soils of the subtropics treated with organic materials. Soil Biol. Biochem. 37: 1507-1518.

Kong, A.Y.Y., J. Six, D.C. Bryant, R.F. Denison, and C. van Kessel. 2005. The relationship between carbon input aggregation, and soil organic carbon stabilization in sustainable cropping systems. Soil Sci. Soc. Am. J. 69: 1078-1085.

Kumar, A. and D.S.Yadav. 1995. Use of organic manure and fertilizer in rice (Oryza sativa)-wheat (Triticum aestivum) 
cropping system for sustainability. Indian J. Agric. Sci. 65:703-707.

Larson, W.E. and F.J. Pierce. 1994. The dynamics of soil quality as a measure of sustainable management. p. 37-51. In J.W. Doran et al. (ed.) Defining soil quality for a sustainable environment. SSSA Spec. Publ. 35. SSSA and ASA, Madison, WI.

Lee, C.H., M.S. Yang, K.W. Chang, Y.B. Lee, K.Y. Chung, and P.J. Kim. 2005. Reducing nitrogen fertilizer level of rice(Oryza sativa L.) by silicate application in Korean paddy soil. Korean J. Soil Sci. Fert. 38(4): 194-201.

Lee, C. H., S. Y. Kim, M. B. Villamil, P. Pramanik, C. O. Hong, and P. J. Kim. 2012. Different response of silicate fertilizer having electron acceptors on methane emission in rice paddy soil under green manuring. Biol. Fertil. Soils. 48:435-442.

Lee, C.H., U.G. Kang, K.D. Park, D.K. Lee, and P.J. Kim. 2008. Long-Term Fertilization Effects on Rice Productivity and Nutrient Efficiency in Korean Paddy. J. Plant Nutr. 31: 1496-1506.

Li, Z.P., M. Liu, X.C. Wu, F.X. Han, and T.L. Zhang. 2010. Effects of long-term chemical fertilization and organic amendments on dynamics of soil organic $\mathrm{C}$ and total $\mathrm{N}$ in paddy soil derived from barren land in subtropical China. Soil Tillage Res. 106: 268-274.

Lian, S. 1976. Silica fertilization of rice. In the fertility of paddy soils and fertilizer application for rice, pp. 197-220. Food fertilizer technology center. Taipei. Taiwan.

Ma, JF., K. Nishimura, and E, Takahashi. 1989. Effect of silicon on the growth of rice plant at different growth stages. Soil Sci. Plant Nutr. 35:347-356

NAAS. 2010. Fertilizer application recommendations for crop plants, National Academy of Agricultural Science, RDA, Suwon, Korea.

Nannipieri, P., B. Ceccanti, and S. Grego. 1990. Ecological significance of the biological activity in soil, pp. 293-355. In: Bollag JM, Stotzky G (eds) Soil biochemistry, vol 6. Marcel Dekker Inc, New York.

Nannipieri, P., E. Kandeler, and P. Ruggierro. 2002. Enzyme activities and microbial and biochemical processes in soil. In: Burns RG, Dick RP (eds) Enzymes in the environment-activity, ecology and applications, pp. 18-22. Marcel Dekker Inc, New York.
Potter, K.N., H.A. Torbert, O.R. Jones, J.E. Matocha, J.E. Morrison Jr, and P.W. Unger. 1998. Distribution and amount of soil organic $\mathrm{C}$ in long-term management systems in Texas. Soil Tillage Res. 47: 309-321.

Ross, D.J. 1992. Influence of sieve mesh size on estimates of microbial carbon and nitrogen by fumigation extraction procedures in soils under pasture. Soil Biol. Biochem. 24: 346-350.

Rudrappa, L., T.J. Purakayastha, D. Singh, and S. Bhadraray. 2006. Long-term manuring and fertilization effects on soil organic carbon pools in a Typic Haplustept of semi-arid sub-tropical India. Soil Tillage Res. 88: 180-192.

Silveira, M.L., N.B. Comerford, K.R. Reddy, W.T. Cooper, and H. El-Rifai. 2008. Characterization of soil organic carbon pools by acid hydrolysis. Geoderma. 144: 405-414.

Singh, J. and J.P. Singh. 1995. Land degradation and economic sustainability. Ecol. Econ. 15, 77-86.

Schofield, R. K. 1949. Effect of pH on electric charges carried by clay particles: J. Soil Sci. 1: 1-8.

Sparling, G.P. and A.W. West. 1988. A direct extraction method to estimate soil microbial $\mathrm{C}$ : Calibration in situ using microbial respiration and 14C labeled cells. Soil Biol. Biochem. 20: 337-343.

Takahashi, E., J.F. Ma, and Y. Miyake. 1990. The possibility of silicon as an essential element for higher plants. Comments Agric. Food Chem. 2: 99-102.

Trinsoutrot, I., S. Recous, B. Bentz, M. Lineres, D. Cheneby, and B. Nicolardot. 2000. Biochemical quality of crop residues and carbon and nitrogen mineralization kinetics under nonlimiting nitrogen conditions. Soil Sci. Soc. Am. J. 64: 918-926.

Vance, E.D., P.C. Brookes, and D.S. Jenkinsen. 1987. An extraction method for measuring soil microbial biomass $\mathrm{C}$. Soil Biol. Biochem. 19: 697-702.

Yadav, R.L. 1998. Factor productivity trends in a rice-wheat cropping system under long-term use of chemical fertilizers. Exp. Agric. 34, 1-18.

Yoshida, S., S.A. Navasero, and E.A. Ramires. 1969. Effects of soilca and nitrogen supply on some leaf characters of the rice plant. Plant Soil. 31: 48-56.

Zhen, L., M.A. Zoebisch, G. Chen, and Z. Feng. 2006. Sustainability of farmers' soil fertility management practices: A case study in the North China Plain. J. Environ. Manage. 79: 409-419. 